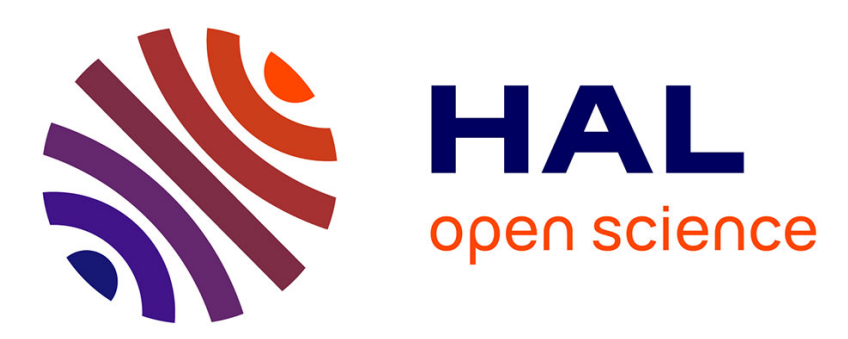

\title{
Ethical key issues and fundamental rights in paediatric research
}

\author{
Annagrazia Altavilla
}

\section{To cite this version:}

Annagrazia Altavilla. Ethical key issues and fundamental rights in paediatric research. European Journal of Clinical Pharmacology, 2010, 67 (S1), pp.117-123. 10.1007/s00228-010-0929-8 . hal00642940

\section{HAL Id: hal-00642940 \\ https://hal.science/hal-00642940}

Submitted on 20 Nov 2011

HAL is a multi-disciplinary open access archive for the deposit and dissemination of scientific research documents, whether they are published or not. The documents may come from teaching and research institutions in France or abroad, or from public or private research centers.
L'archive ouverte pluridisciplinaire HAL, est destinée au dépôt et à la diffusion de documents scientifiques de niveau recherche, publiés ou non, émanant des établissements d'enseignement et de recherche français ou étrangers, des laboratoires publics ou privés. 


\title{
ETHICAL KEY ISSUES AND FUNDAMENTAL RIGHTS IN PAEDIATRIC RESEARCH ${ }^{1}$
}

\section{Annagrazia ALTAVILLA}

Lawyer at the Bar of Taranto (Italy),

Associated Senior Lecturer at Université de la Méditerranée - Marseille (France)

Espace Ethique Méditerranéen (E.A.3783)

Hôpital Adultes de la Timone

264, Rue Saint Pierre - 13385 CEDEX 5 Marseille (France)

annagrazia.altavilla@univmed.fr

Tel : 0033(0)491384427

\begin{abstract}
Research involving children is necessary for the continued advancement of children's health and welfare. However, paediatric research necessitates a compromise between advances in medical knowledge and the exposure of children to risk. A large number of ethical guidelines and texts of varying legal force exist in the field of clinical research and in particular related to paediatrics. Differences, tensions or outright contradictions among the provisions of these texts can generate confusion leading to the adoption of different ethical standards. In this context, the real challenge is to ensure that each child involved in a clinical trial in the EU territory may rely directly to the same principles and rights. Taking international human rights law as the essential framework and starting point for the development of universal ethical principles relevant for paediatric research is a way to guarantee the application of the principle of equality of treatment, based on the respect of fundamental rights. The implementation, at national and local level, of the European Ethical Recommendations, based on international human rights law, seems to be the next step to develop quality and ethically sound paediatric research.
\end{abstract}

Keywords : clinical research, children, ethics, fundamental rights, trials

\section{INTRODUCTION}

The main objective of clinical research is to develop generalizable knowledge to improve health and/or increase understanding of human biology. Ethical requirements for clinical research aim at minimizing the possibility of exploitation by ensuring that research subjects are not merely used but are treated with respect while they contribute to the social good [1].

Clinical research on children raises many scientific and ethical concerns [2]. With respect to paediatric population, there are significant deficits in the objective knowledge of quality and efficacy of current preventive measures, pharmacokinetics and pharmacodynamics of medications, appropriate dosage and application form for different age periods, and of the adequacy of deriving children's doses from adult studies [3]. The off-label or even off-licence use of medicine on children can have detrimental consequences in terms of unexpected adverse reactions and of access to the most up-to-date treatments.

Recently, the need to stimulate paediatric research in Europe has resulted in regulatory measures to facilitate and support clinical trials in this field [4]. The call for more medical research involving children has also

\footnotetext{
${ }^{1}$ Part of TEDDY Supplement
} 
raised the question whether the law as it stands strikes an appropriate balance between the need for clinical trials and the interests and rights of the child. While there is general agreement that children should be given special protection as research subjects, there are also concerns that too restrictive regulation may hinder research serving their long term health interests [5].

Article 1 of the Universal Declaration of Human Rights expresses the basic right of all human beings to be free and equal in dignity and rights [6]. The main ethical and legal imperative of all paediatric activities is to do everything "in the best interests of children"[7]. The United Nations Convention on the Rights of the Child [7] asserts that children have the right to say what they think should happen when adults make decisions that affect them and to have their opinions taken into account (article 12), have the right to get and share information (article 13), have the right to think and believe what they want and practice their religion as long as they do not stop other people enjoying their rights (article 14) and have the right to privacy (article 16). All these assume growing levels of capacity to consent, which have to be taken seriously. As children develop, it should be the degree of their maturity which determines when they are regarded as fully competent and capable of autonomous decisions. This will vary child to child.

Apart from the general requirements of research on human subjects such as an adequate informed consent, a balance between risks and benefits, additional rules and principles have been developed at international and European level in order to protect the best interests of the children involved in clinical research. Furthermore, relevant guidelines can be derived from the UN Declaration on the rights of the child, whereupon every child has the fundamental right to life and dignity, and is entitled to optimal care, based on the scientific evaluation of preventive, diagnostic and therapeutic measures. Paediatric care includes the responsibility to achieve the highest level of knowledge, consideration of the child-specific somatic, mental and social development, emphatic and trustworthy communication with the child and parents [8].

In this article we will describe the methodology of "ethical reasoning" that finally led TEDDYNoE (Taskforce in Europe for Drug Development for the Young - Network of Excellence) to propose, during the consultation process [9], the integration of international human rights law in the "European Ethical Recommendations on clinical trials involving minors", finally approved by the European Commission in 2008 [10]. This document aims at facilitating the conduct of paediatric clinical trials in the EU and at contributing to the protection of children involved.

\section{METHODOLOGY}

\section{Ethical principles and guidelines}

According to the main international declarations and guidelines [11, 12, 13, 14, 15], all research involving human subjects should be conducted in accordance with three basic ethical principles, namely respect for persons, beneficence and justice.

Respect for persons incorporates at least two fundamental ethical considerations: a) respect for autonomy, which requires that those who are capable of deliberation about their personal choices should be treated with respect for their capacity for self-determination; and b) protection of persons with impaired or diminished autonomy, which requires that those who are dependent or vulnerable be afforded security against harm or abuse.

"Vulnerability" refers to a substantial incapacity to protect one's own interests owing to such impediments as lack of capability to give informed consent, lack of alternative means of obtaining medical care or other expensive necessities, or being a junior or subordinate member of a hierarchical group. Accordingly, special provision must be made for the protection of the rights and welfare of vulnerable persons, as minors [16]. 
Beneficence refers to the ethical obligation to maximize benefits and to minimize harms. This principle gives rise to norms requiring that the risks of research be reasonable in the light of the expected benefits, that the research design be sound, and that the investigators be competent both to conduct the research and to safeguard the welfare of the research subjects. Justice refers to the ethical obligation to treat each person in accordance with what is morally right and proper. In the field of research the principle refers primarily to distributive justice, which requires the equitable distribution of both the burdens and the benefits of participation in research.

In the light of these principles, consensus is emerging concerning what elements are necessary requirements for the ethical conduct of clinical research. These include: scientific value and validity, favorable risk-benefit ratio, fair subject selection, informed consent, independent review and respect of subjects [17].

So, to be ethical, clinical research must be valuable, meaning that it evaluates a diagnostic or therapeutic intervention that could lead to improvements in health or well-being; or tests a hypothesis that can generate important knowledge about structure or function of human biological systems, even if that knowledge does not have immediate practical ramifications [17, 18].

A valuable research must be conducted in a methodologically rigorous manner. The methods must be valid and practically feasible: the research must have a clear scientific objective; it has to be designed using acceptable principles, methods and reliable practices; it has sufficient power to definitively test the objective and offer a plausible data analysis plan. In addition, it must be possible to execute the proposed study $[17,18]$. Paediatric research design should employ wherever possible child-friendly settings, personnel and procedures that limit invasiveness to a meaningful minimum [19].

Scientific goals of the study have to be the primary basis for determining the groups and individuals that will be recruited and enrolled, both through the development of a strategy and specific inclusion and exclusion criteria that, in case of paediatric research, explicitly recognize the vulnerability of children [20].

Clinical research can be justified only if, in accordance with the scientific aims of the study and the relevant standards of clinical practice, the potential risks to individual subjects are firstly identified and minimized. To this aim, procedures which are consistent with sound research design and which do not necessarily expose subjects to risk should be used, and whenever appropriate, procedures already being performed on the subjects for diagnostic or treatment purposes should be adopted [18]. Secondly, the health-related potential benefits of the research to individual subjects are to be delineated and enhanced. Finally, the potential benefits to individual subjects and society have to proportionate to or outweigh the risks.

In the evaluation of the expected impact on an individual patient or a group of a proposed research, benefits can be of several kinds: advancing the patient's or society's interests, producing new knowledge of value to future patients or devising a policy which advances the common good. Risks are the estimates of probabilities or possibilities of injuring a patient or a group, for example producing harms that violate the interests of the research subjects. Harms may be financial, physical, emotional or spiritual, singly or in combination [20].

When dealing with paediatric research it is necessary to be more risk averse and seek evidence of direct personal benefits or benefits to their own class of persons as a result of research participation. Benefits should be evaluated conservatively, whereas harms are assessed more broadly [21]. Benefits must be apparent to the individual child or to children in general or the research cannot be pursued even if involving minimal risk. Harms must be assessed from the perspective of the child and be sensitive to the child's lesser capacity to understand what is going on, the effects of disruptions, inconvenience and novel situations on the child and family [21]. 
The threshold for harm in children uses the standard of "minimal risk" and "minimal burden" beyond which specific justification for such risk/burden exposure must be present. The research bears a minimal risk if, having regard to the nature and scale of the intervention, it is to be expected that it will result, at the most, in a very slight and temporary negative impact on the health of the person concerned. It bears a minimal burden if it is to be expected that the discomfort will be, at the most, temporary and very slight for the person concerned. In assessing the burden for an individual, a person enjoying the special confidence of the person concerned shall assess the burden where appropriate [22].

Nobody should be forced to engage in activities inconsistent with his or her own values, interests and preferences. Freely given informed consent is the foundation stone of contemporary ethics of clinical research. It can be withdrawn at any moment without any prejudice, liability or discrimination against the participants in the research. Consent requires that the individual be competent. Due to developmental and cognitive limitations, children are not yet competent persons, meaning that they are not capable of providing legal consent to research participation [23].

In the absence of the capacity to provide consent, permission for research participation must be sought from a proxy, taking into account the best interests of the child $[24,26]$. Legal representatives have to put foremost choices that preserve well-being and maintain the capacity of the child to ultimately develop into autonomous decision-maker [25]. Child's assent or dissent has to be considered as a lower level of decisionmaking capability that is developmentally determined. The research should not start or be discontinued if the child raises objections or resistance. Children must be solicited in an appropriate manner sensitive to their current cognitive and developmental abilities. Well-crafted age appropriate informational materials should aid investigators in explaining to potential child research participants exactly which elements of their medical care are research, and therefore optional [27, 28].

Another essential requirements for ethical conduct of research is the independent review of clinical protocols by an Ethics committee. This provides a mechanism for third-party validation separate from the vested interests of investigators that ensures that scientific and ethical standard are being met. It is a means of keeping in check potential conflicts of interests, protecting the welfare of subjects, allowing for transparency and finally providing public (i.e. social) accountability that is reassuring to potential subjects [21].

To guarantee the well-being and rights of children participating in a clinical research, protocols have to be endorsed by an Ethics committee with paediatric expertise or after taking advice in clinical, ethical and psychological problems in the field of paediatrics [29].

Finally, providing participants in clinical research additional information about the effect of the intervention or the subject's clinical condition learned from the research, protecting confidentiality and monitoring wellbeing are key aspects of an ethical research to guarantee the respect for persons and their autonomy, in the light of the principles of beneficence and non-maleficence.

\section{Legal framework}

At European level, Oviedo Convention [34] and Clinical trial Directive 2001/20/EC [29] establish that the accepted basis for the conduct of clinical trials in humans is founded on the protection of human rights (namely the right to life, to physical and mental integrity and to privacy) as well as human dignity, that is "the cardinal principle of the legal norms relating to bioethics" [30].

As a direct corollary of the human dignity, these documents affirm the primacy of the human being over science and society and emphasize two fundamental ideas: first, that science is not an end in itself but only a 
means for improving the welfare of individuals and society; second, that people should not be reduced to mere instruments for the benefit of science.

Besides, through the incorporation of the ICH Guidance on Good Clinical Practice and its effective adoption as binding law, Directive can be seen as affording protection to individual research participants, and especially to vulnerable subjects (e.g. children). To this aim, Directive 2001/20/EC devotes a specific article (art. 4) to minors' protection.

Nevertheless, even if all the European countries implemented Directive 2001/20/EC, with respect to clinical research practices in paediatrics, it exists a "regulatory gap" or rather a "regulatory conflict" not only among ethical and legal frameworks at European level but, most of all, between the European ethical/legal frameworks (Directive 2001/20/EC, Oviedo Convention, Additional Protocol on Biomedical research, etc.) and national regulations [31].

Many differences exist in Europe related to the guarantees of children rights, to the protection of minors involved in clinical trials across Europe as well as to the ethical reviewing of paediatric protocols [32, 33]. Some countries go beyond the requirements of the Directive: for instance they assure more importance to the will of the minors (Spain) or consider their will necessary to involve them in clinical trials (Denmark, Estonia and the Netherlands). The expression of will is accepted at different age limits (12 years in Spain, 15-17 years in Denmark, 7-17 years in Estonia, 12 years in The Netherlands) [31, 32].

With reference to acceptable risk and burden for children involved in clinical research, Greece, Ireland, Italy, and Belgium would seem to follow the more liberal Directive (requiring "minimising" risk and burden, also if there is only group benefit). The Netherlands, France and Finland seem to follow the stricter Additional Protocol on Biomedical research [22], that requires minimal risk and burden if there is only group benefit $[33,46-50]$.

Furthermore, the wide range of situations due to a no-coordinate Directive 2001/20/EC implementation, the great differences in cultural and economic environment, the large number of texts of varying legal force existing in the field of clinical research, with special reference to paediatrics, can cause difficulties in imposing penalties on researches that violate human rights of minors in the name of medical research. In this context, it was imperative to have a systematic and coherent framework for evaluating clinical studies that incorporates all relevant ethical considerations.

\section{International Human Rights Law and European Ethical recommendations}

In 2008, the ad hoc group for the development of implementing guidelines for Directive 2001/20/EC, chaired by the European Commission, approved the document "Ethical Considerations for Clinical Trials on Medicinal Products with the Paediatric Population"[10]. According with proposals submitted by TEDDYNoE during consultation process [9], these recommendations integrate principles contained in all the international/European ethical/legal sources relevant for biomedical research and consistent with the international human rights law [6,7, 11-16, 22, 29, 34-41].

The purpose was to ensure that each minor involved in a clinical trial in the EU territory may rely directly to the same principles and rights in order to apply the principle of equality of treatment that is an implicit milestone in building a European wide-democratic society, based on the respect of fundamental rights.

"The human rights framework" provides a more useful approach for analyzing and responding to modern public health challenges that any framework thus far available within the biomedical tradition" [42]. Since the adoption of the Universal Declaration of Human Rights in 1948, a large number of international 
instruments have been adopted to ensure the unconditional respect for the human person in very diverse contexts. Furthermore, the existing human rights system, with its extensive body of international standards and wide range of follow-up mechanisms, represents one of the most remarkable achievements of our time. Therefore, it is important to make use of this rich normative and institutional set-up in order to protect people from harm in the field of biomedicine [52].

All the above mentioned sources [6,7, 11-16, 22, 29, 34-41] address ethical issues related to medicine, life sciences and associated technologies as applied to children, taking into account their social, legal and environmental dimensions, as well as the necessity to protect individuals and groups of special vulnerability (as children) and to respect the personal integrity of such individuals.

Since the respect of fundamental rights constitutes, in value systems recognized in Europe, an indivisible obligation for the public authority to fulfill, the methodological approach aimed at integrating human rights law seemed to be particularly useful to recognize the importance of freedom of research and the benefits derived from scientific and technological developments, while providing a universal framework of principles and procedures to guide EU and States in the formulation of their legislation, policies or other instruments in the field of bioethics and paediatric clinical research.

The methodology of using international human rights ethical reasoning in developing a European ethical framework for paediatric research is based on the awareness of interrelation and complementarity of the principles contained in all the ethical/legal European/international sources as well as of the pluralistic and non-hierarchical relationship existing between these principles. The extent to which principles referred to in various documents (both legal and ethical instruments) are taken into account in national or regional legislation within EU is variable. They overlap in many areas, but some give greater precision on certain points whilst on others there are differences in approach.

In case of tensions or outright contradictions among the provisions of the various guidelines related to clinical research [43], conflicts should be solved by finding a balance between competing principles, taking into account the "highest-ethical standards" (as standards providing with more guarantees) with the aim to protect health and rights of the child. The legal value of the source or a culturally sensitive interpretation of the principle shall be considered as well.

In such a sensitive field as bioethics and clinical research, where socio-cultural, philosophical and religious traditions come into play, using human rights framework should facilitate the formulation of universal standards, because international human rights law is based on the assumption that some basic rights transcend cultural diversity.

So, the mentioned methodology aimed at founding ethical reasoning on human rights provided European ethical recommendations with an opportunity to be accepted by different cultures and traditions, even outside Europe. European ethical Recommendations, expected to facilitate a coordinated approach to the application of the Clinical Trial Directive across the EU, with special reference to paediatric research, are also relevant to clinical trials conducted in non-EU countries especially developing countries.

These Recommendations integrate the Clinical Trial Directive provisions and clarify the process of assessment of the benefit and risk balance, the process of information and consent/assent according to age groups and level of minors' maturity and the process of ethical review of paediatric protocols. They also deal with individual data protection and insurance issues. The main principles are, first, that children may not be included in clinical trials if the same results can be obtained using adults. Second, whenever possible the research should have a direct benefit for the children involved; without such a benefit, the risks must be strictly limited and every effort must be made to reduce pain, discomfort and fear. Third, parents or 
guardians must be fully informed and have given consent for the participation of their child; minors should be involved in the informed consent process in proportion to age and degree of maturity.

In particular, with reference to consent/assent process, new EC recommendations specify that separate information sheets for adults and children, and separate consent and assent forms should be used in order to provide age appropriate information, in language and wording appropriate to age, psychological and intellectual maturity. Assent, like consent, is a continuous process and should be sought during the trial as well. The information process provided to the child and the child's response should be documented. Every effort should be made to understand and respect differences of opinion between the child and his/her parents or legal representative. Strong and definitive objections from the child should be respected.

With reference to paediatric expertise to be included in the Ethics committee in charge of reviewing protocols, it is underlined that this expertise goes beyond having dealt with children and could be defined on the basis of education and experience on the various aspects of child development, ethics and psychosocial aspects. Furthermore, qualifications and expertise of the experts used and the members of the Ethics Committee should be documented and annexed to its opinion.

Finally, ethical standards, principles and requirements contained in the European Ethical Recommendations could be reinterpreted, refined and revised with changes in science and experience. Nevertheless, being human rights the standard-setter in bioethics, according to the art. 27 of the Universal Declaration on Bioethics and Human Rights, any limitation on the application of these principles needs to be consistent with the international human rights law [37].

\section{Conclusions}

The ethical conduct of clinical research in children is challenged by the inherent vulnerability of this population. Children should enjoy the benefits of clinical research but they should be protected from harms to their health and well-being. Even if these two objectives seem to be partly incompatible [2, 51], it is important to balance them in order to meet the specific therapeutic needs of the paediatric population, without subjecting this population to unnecessary trials. Thus, trials involving children are on trial [44].

The European Paediatric Regulation provides rewards, incentives and obligations for pharmaceutical companies to facilitate the development and availability of high-quality medicines for children. Meanwhile, high ethical standards, the education and training of investigators in good clinical practice as well as the protection of health and rights of children involved in clinical trials are needed. The ethical obligation to assess interventions in children should override drug profitability projections [44].

Thus, the real challenge is to translate ethical principles into clinical research and to establish procedures that are consistent with human rights international law, both ethically sound and culturally sensitive, although there may be times when these two requirements appear to be in conflict.

In this context, the European Ethical Recommendations, providing an ethical framework based on international human rights law, leads to explicit heightened universal standards of ethical propriety that seek to balance the real need to conduct research and the need to protect children from the exploitation of their vulnerability.

It is our collective responsibility to promote the application of these updated rules. To this aim efforts are needed at both regulatory and scientific levels to implement these ethical standards at national and local level. It shall be also essential to increase the awareness of the ethical aspects of paediatric research and to promote public debates, education and training initiatives involving main stakeholders (e.g. sponsors, investigators, ethics committees, regulatory bodies, patients associations).

This methodological approach is crucial in the perspective of the internationalization of research that creates new responsibilities, particularly regarding research carried out in developing countries under the scientific 
and financial control of developed nations. To develop sound ethical principles intertwined with international human rights law and facilitate their implementation globally would contribute to the development of research of high quality that respects the fundamental rights of each individual and is a source of progress for the health and welfare of everyone across the globe.

\section{Conflict of interest disclosure statement}

Coordinator of activities in the field of Ethics of TEDDYNoE (Task-force in Europe for Drug Development for the Young -Network of Excellence - founded in the framework of EU FP6, contrat n.LSHBCT-2005005126). None to declare.

\section{Acknowledgements:}

This contribution is part of the Task-force in Europe for Drug Development for the Young (TEDDY) Network of Excellence supported by the European Commission's Sixth Framework Program (Contract $\mathrm{n}$. 0005216 LSHBCT- 2005-005126).

\section{REFERENCES}

[1] Levine RJ (1988) Ethics and regulation of clinical research (2 ${ }^{\text {nd }}$ ed.) New Haven, CT: Yale University Press.

[2] Oberman M, Frader J (2003) Dying children and medical research: access to clinical trials as benefits and burden, 29 (2-3): 301-317

[3] Gill D (2004) Ethical principles and operational guidelines for good clinical practice in paediatric research. Recommendations of the Ethics Working Group of the Confederation of European Specialists in paediatrics (CESP). Eur. Jnl. Paediatrics, 163:53-57.

[4] Regulation (EC) n.1901/2006 of the European Parliament and of the Council on medicinal products for paediatric use, amended by Regulation (EC) n.1902/2006. OJEC L 378 of 27 December 2006 :1-19.

[5] Gevers JKM (2008) Editorial. Medical research involving children. European Journal of Health Law, 15(2):103-108.

[6] United Nations General Assembly (1948) Universal Declaration of human rights http://www.un.org/en/documents/udhr/ Accessed July 2009

[7] United Nations General Assembly (1989) Convention on the Rights of the Child http://www2.ohchr.org/english/law/crc.htm accessed July 2009.

[8] Kurz R, Gill D, Mjones S (2006) Ethical issues in the daily medical care of children. Eur J Paediatr 165:83-86.

[9] Recommendations on ethical issues on medicine for children for European and National Institutions http://www.teddyoung.org/download/9 RecommendationsonethicalissuesonmedicineforchildrenforEuropean andNationalInstitutionspreparation(includingissuesonclinicaltrials).pdf Accessed July 2009 
[10] "Ethical considerations for clinical trials performed in children - Recommendations of the Ad hoc group for the development of implementing guidelines for Directive 2001/20/EC relating to good clinical practice in the conduct of clinical trials on medicinal products for human use" (2008) Eudralex vol-10.

http://ec.europa.eu/enterprise/pharmaceuticals/paediatrics/docs/paeds_ethics_consultation20060929.pdf Accessed July 2009

[11] Declaration of Helsinki of the World Medical Association (2008) http://www.wma.net/e/policy/b3.htm Accessed July 2009.

[12] CIOMS - WHO (2002) International Ethical Guidelines for Biomedical Research Involving Human Subjects. http://www.cioms.ch/frame_guidelines_nov_2002.htm Accessed July 2009

[13] International Conference on Harmonization of Technical Requirements for the Registration of Pharmaceuticals for Human Use - ICH -Guideline for Good Clinical Practice E6 (R1), CPMP/ICH/135/95 of 10 July 1996. http://www.emea.europa.eu/pdfs/human/ich/013595en.pdf Accessed July 2009

[14] Clinical investigation of medicinal products in the paediatric population E11, Note for guidance on clinical investigation of medicinal products in the paediatric population, CPMP/ICH/27H/99. http://www.emea.europa.eu/pdfs/human/ich/271199en.pdf Accessed July 2009

[15] The Belmont Report, The Ethical Principles and Guidelines for the Protection of Human Subjects of Research, National Commission for the Protection of Human Subjects of Biomedical and Behavioral Research, 1979, http://ohsr.od.nih.gov/guidelines/belmont.html accessed July 2009.

[16] CIOMS-WHO (2009) International Ethical Guidelines for Epidemiological Studies, http://www.cioms.ch/frame_ethical_guidelines_2009.htm accessed July 2009

[17] Emanuel EJ, Wendler D, Grady C (2000) What makes clinical research ethical, JAMA 283 (20):27012711.

[18] Vanderpool HY (1996) The ethics of research involving human subjects. Frederick MD, University Publishing Group:45-58.

[19] Werthorn LA, Scherer DG, Children's involvement in research participation decisions, in Grodin MA, Glantz LH (1994) Children as research subjects. Science, Ethics and Law, Oxford, Oxford University Press: 133-179.

[20] Beauchamp TL, Childress JF (2001) Principles of biomedical ethics, $5^{\text {th }}$ Edition. Oxford University Press, New York.

[21] Shevell MI (2002) Ethics of clinical research in children, Seminars in Paediatric Neurology, 9(1):46-52.

[22] Council of Europe, Additional Protocol to the Convention on Human Rights and Biomedicine, concerning Biomedical Research, CETS N.195, 25 ${ }^{\text {th }}$ January 2005, came into force on the $1^{\text {st }}$ of September 2007. http://conventions.coe.int/Treaty/en/Treaties/Html/195.htm Accessed July 2009

[23] Burke TM, Abramovitch R, Zlotkin S (2005) Children's understanding of the risks and benefits associated with research, J.Med. Ethics, 31:715-720. 
[24] Levy MDL, Larcher V, Kurz R (2003) Informed consent/assent in children. Statement of the Ethics Working Group of the Confederation of European Specialists in Paediatrics (CESP). Eur J Pediatr, 162:629633.

[25] Rossi WC, Reynolds W, Nelson RM (2003) Child assent and parental permission in paediatric research. Theorical Medicine 24:131-148.

[26] Rothmier JD, Lasley MV, Shapiro GG (2003) Factors influencing consent in paediatric clinical research. Paediatrics, 111:1037-1041.

[27] Ungar D, Joffe S, Kodish E (2006) Children are not small adults: documentation of assent for research involving children. The Journal of Paediatrics, 149(1): 31-33.

[28] Chappuy H, Gary A, Chéron G, Tréluyer JM (2005) Le consentement dans les essays cliniques pédiatriques. Archives de pédiatrie 12:778-780

[29] Directive 2001/20/EC of the European Parliament and of the Council of 4 April 2001 on the approximation of the laws, regulations and administrative provisions of the Member States relating to the implementation of good clinical practice in the conduct of clinical trials on medicinal products for human use, OJEC L121 of 1 May 2001:34-44.

[30] Lenoir N, Mathieu B (1998) Les Normes internationales de la bioéthique PUF, Paris, p.16

[31] Altavilla A, Giaquinto C, Ceci A (2008) European survey on ethical and legal framework of clinical trials in paediatrics: results and perspectives. Journal International de Bioéthique, 19 (3):17-48

[32] Altavilla A, Giaquinto C, and others, (2009) Activity of Ethics Committees in Europe on issues related to clinical trials in paediatrics: results of a survey. Pharmaceutical Policy and Law, 11:1-9.

[33] Altavilla A (2008) Clinical research with children: the European legal framework and its implementation in French and Italian law. Eur J Health Law. 15(2):109-125.

[34] Council of Europe, (1997) Convention for the Protection of Human Rights and Dignity of the Human Being with regard to the Application of Biology and Medicine: Convention on Human Rights and Biomedicine. ETS n.164 http://conventions.coe.int/Treaty/en/Treaties/Html/164.htm Accessed July 2009

[35] Charter of Fundamental Rights of European Union, OJEC C364 of 18 December 2001:1-22. http://www.europarl.europa.eu/charter/pdf/text_en.pdf Accessed July 2009

[36] UNESCO, Universal Declaration on the Human Genome and Human Rights (1997) http://portal.unesco.org/en/ev.php-URL_ID=13177\&URL_DO=DO_TOPIC\&URL_SECTION=201.html Accessed July 2009.

[37] UNESCO, Universal Declaration on Bioethics and Human Rights (2005) http://portal.unesco.org/en/ev.php-URL ID=31058\&URL DO=DO TOPIC\&URL SECTION=201.html Accessed July 2009

[38] UNESCO, International Declaration on Human Genetic Data (2003) http://portal.unesco.org/en/ev.phpURL_ID=17720\&URL_DO=DO_TOPIC\&URL_SECTION=201.html Aaccessed July 2009 
[39] Directive 2005/28/EC of 8 April 2005 laying down principles and detailed guidelines for good clinical practice as regards investigational medicinal products for human use, as well as the requirements for authorization of the manufacturing or importation of such products, OJEC L91 of 9 April $2005: 13-19$.

[40] Directive 95/46/EC of the European Parliament and of the Council of 24 October 1995 on the protection of individuals with regard to the processing of personal data and on the free movement of such data, OJEC L 281 of 23 November $1995: 31-50$

[41] EC Detailed guidance on the application form and documentation to be submitted in an application for an ethics Committee opinion on a clinical trial on medicinal products for human use (2006) http://ec.europa.eu/enterprise/pharmaceuticals/eudralex/vol-10/12_ec_guideline_20060216.pdf Accessed July 2009

[42] Mann J (1996) Health and human rights. Protecting human rights is essential for promoting health. British Medical Journal, vol.312:924.

[43] Edwards SD, McNamee MJ (2005) Ethical concerns regarding guidelines for the conduct of clinical research on children, J Med Ethics, 31: 351-354.

[44] Caldwell PHY, Murphy SB, Butow PN, Craig JC (2004) Clinical trials in children. Lancet 364:803-811.

[45] Buchner B, Hart D (2008) Research with minors in Germany. European Journal of Health Law, 15(2):127-134.

[46] Lötjönen S (2008) Medical research on minors in Finland. European Journal of Health Law, 15(2):135144.

[47] Kenter MJH (2008) Legislation and review of medical research with minors in The Netherlands. European Journal of Health Law, 15(2):145-151.

[48] Pinxten W, Dierickx K, Nys H (2008) The implementation of Directive 2001/20/EC into Belgian law and specific provisions on paediatric research. European Journal of Health Law, 15(2):153-161.

[49] Canellopoulou-Bottis M (2008) Research with minors in Greece and the EU Directive on clinical trials. European Journal of Health Law, 15(2):163-168.

[50] Sheikh AA (2008) Ireland and medical research with minors: some medico-legal aspects. European Journal of Health Law, 15(2):169-181.

[51] Meaux JB, Bell PL (2001) Balancing recruitment and protection: children as research subjects. Iss Comp Paediatr nursing, 24: 241-251.

[52] Ten Have HAMJ, Jean MS (2009) The Unesco Universal Declaration on bioethics and Human rights, background, principles and application. UNESCO, Paris. 